\title{
Effect of differential nerve block on inhibition of the monosynaptic reflex by vibration in man
}

\author{
G . M O D D E L, B . B E S T, A N D P . A S H B Y \\ From Toronto Western Hospital, Toronto, Canada
}

SUMMARY The differential nerve block produced by ischaemia has been used in an attempt to identify the afferent nerve fibres responsible for vibratory inhibition of the monosynaptic reflex in man. It is concluded that the inhibition arises mainly from receptors in the lower leg and is carried by myelinated afferent fibres larger than A-delta.

Vibration of a limb in man results in a powerful inhibition of the monosynaptic reflexes of that limb (Hagbarth, 1973; Lance et al., 1973). The degree of vibratory inhibition is altered after lesions of the motor system (Delwaide, 1973; Ashby and Verrier, 1975, 1976), but interpretation of this finding is limited as the mechanism of vibratory inhibition remains incompletely understood. In the experimental animal inhibition of monosynaptic reflexes can be produced by vibration of $50 \mu \mathrm{m}$ which excites only the spindle primary endings. The inhibition is accompanied by depolarisation of primary afferent fibres, it can be blocked by picrotoxin, and it can occur while the excitability of motoneurones to direct stimulation is unchanged. These observations led Gillies et al. (1969) and Barnes and Pompeiano (1970) to suggest that the effect resulted from presynaptic inhibition of Ia afferent fibres. Vibration of a muscle in man, however, is not such a specific stimulus and may activate the secondary spindle endings and Golgi tendon organs in addition to primary spindle endings (Burke et al., 1976). Vibratory inhibition of monosynaptic reflexes in man could, therefore, result from a variety of presynaptic or postsynaptic inhibitory mechanisms. A knowledge of the afferent nerve fibres responsible for the effect would clarify this situation to some extent.

Ischaemia of a limb results in a differential block of nerve fibres, the large fibres being, in general, affected before the small ones (Lewis et al., 1931; Zotterman, 1933; Clark et al., 1935; Magladery et al., 1950; Sinclair and Hinshaw,

Address for correspondence and reprint requests: Dr P. Ashby, 25 Leonard Avenue, Toronto, Ontario M5T 2R2, Canada.

Accepted 25 May 1977
1950; Landau and Bishop, 1953). In the present study a sphygmomanometer cuff was applied to the leg below the knee and inflated above arterial pressure. Transmission in nerve fibres of various sizes was assessed at intervals either clinically or neurophysiologically to document the selectivity of the block. The degree of vibratory inhibition of the $\mathrm{H}$ reflex was measured simultaneously in an attempt to identify the size of the afferent fibres carrying this effect.

\section{Methods}

Studies were performed on seven normal subjects aged 26 to 39 years (mean 32 years). The subjects lay prone with the foot in a padded frame and the ankle joint fixed at $90^{\circ}$. The compound action potentials of the soleus muscle were recorded with two surface electrodes. One electrode was placed in the midline just below the insertion of the heads of gastrocnemius, and the other $80 \mathrm{~mm}$ distally over the tendo Achilles. The action potentials were amplified ( 2 to $5 \mathrm{mV}=10 \mathrm{~mm}$ ), using a Tektronix 5A22N differential amplifier (with band pass $0.1 \mathrm{~Hz}$ to $0.1 \mathrm{MHz}$ ), displayed on a Tektronix $5103 \mathrm{~N}$ storage oscilloscope, and photographed. The peak-to-peak amplitudes of the action potentials were measured from the photographs. The amplitudes of three successive responses were averaged on each occasion.

The direct ( $M$ response) and the reflex ( $\mathrm{H}$ reflex) response of the soleus were elicited with square wave electric stimuli $0.5 \mathrm{~ms}$ duration (maximum frequency $0.5 \mathrm{~Hz}$ ) generated by a Medical Systems Corporation Type 3072 stimulator. The stimuli were delivered to the popliteal nerve in the popliteal fossa using a bipolar stimulating electrode positioned to obtain the $\mathrm{H}$ reflex with the lowest 
threshold. The stimulus current producing the largest $H$ reflex, with a small $M$ response to check for electrode movement, was chosen from the H-M recruitment curve. The Achilles tendon reflex (ATR) was elicited by supramaximal mechanical stimuli delivered to the tendo Achilles with a tendon hammer that triggered the oscilloscope sweep. Vibration was applied to the tendo Achilles using a Wahl 'Jumbo' vibrator (frequency $60 \mathrm{~Hz}$, undamped amplitude $3 \mathrm{~mm}$ ). Vibration was applied for $20 \mathrm{~s}$ before a test reflex was elicited and $90 \mathrm{~s}$ was allowed to elapse after vibration ceased before further reflex measurements were made.

Cutaneous sensory thresholds were measured on the skin over soleus halfway between the recording electrodes. Touch threshold was estimated using an anaesthesiometer (Rowan Products Co., 8744 Cedros Avenue, Panorama City, California 91402) with a range of 0.2 to $1.4 \mathrm{~g}$. (The skin is touched with a plastic filament of known characteristics.) Vibration threshold was estimated using a biothesiometer with a range of $0-25 \mu \mathrm{m}$ at $120 \mathrm{~Hz}$ (Model \#3702M, Biomedical Instrument Company, Newbury, Ohio). A pinprick served to test pain. The threshold for each sensory modality was taken as the stimulus level producing three consecutive correct responses.

When the subject was familiar with the experimental conditions a 'run' of measurements was recorded. The measurements included the amplitudes of the maximum $M$ response, the maximum $\mathrm{H}$ reflex, the maximum $\mathrm{H}$ reflex during vibration, and the ATR. In addition the thresholds for touch, vibration, and pain were estimated. After three control runs had been recorded a sphygmomanometer cuff, placed just below the stimulating electrode in the popliteal fossa, was inflated to $160 \mathrm{mmHg}$ (Fig. 1). Runs were repeated at intervals of approximately $3 \mathrm{~min}$ until the ankle jerk was abolished. The cuff was then released and three further runs were made.

The compound action potential of soleus resulting from supramaximal stimulation of the popliteal nerve ( $M$ response) was considered to represent the activity of all of the motor units of soleus. A reduction in the amplitude of the $M$ response was considered to indicate failure of conduction in a proportion of the alpha motor fibres. This assumption can be justified as the muscle fibre and the neuromuscular junction are less sensitive to ischaemia than motor axons. (Magladery et al., 1950), and there is little dispersal of motor conduction velocities during ischaemia (Hershey and Wagman, 1966; Ruskin et al., 1967). The $\mathrm{H} / \mathrm{M}$ ratio was considered

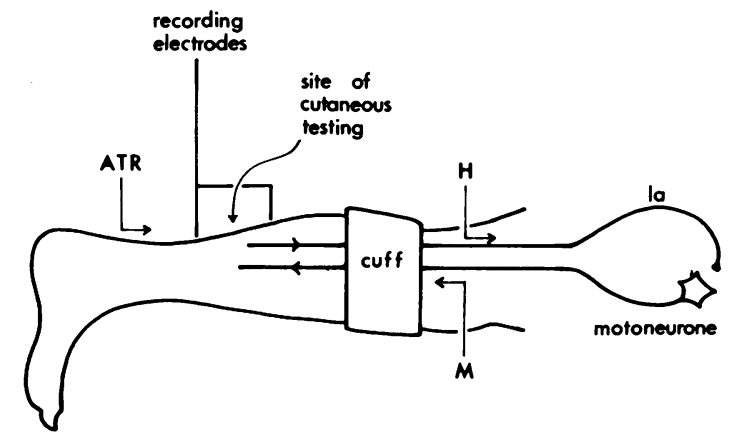

Fig. 1 Diagram of the method. The $M$ response is elicited by supramaximal stimulation of the popliteal nerve above the cuff. Ischaemia will affect the distal portion of the alpha motor fibres. The $H$ reflex is elicited above the cuff. The Achilles tendon reflex ( $A T R)$ is carried by Ia fibres which will become ischaemic below the cuff. Sensory testing was carried out over the soleus so that the length of the nerve fibre rendered ischaemic is the same in each case.

to indicate the proportion of the soleus motoneurone pool that could be excited by Ia fibres stimulated above the cuff. This ratio provides a measure of central excitability. The ATR/M ratio was considered to represent the proportion of the soleus motoneurone pool that could be activated by Ia fibres excited below the cuff. The ATR/H ratio takes into account any changes in central excitability. A reduction in the ATR/H ratio, therefore, indicates failure of conduction in Ia afferent fibres, below the cuff. Fusimotor effects can be ignored as there is no resting fusimotor drive in man (Wallin et al., 1973).

The endpoint of each study was taken when the ATR/H ratio became zero. At this time conduction in Ia afferent fibres was considered to have effectively ceased. Numerical values for the 'percentage of functioning fibres' were obtained as follows (it is recognised that non-linearities are ignored): the percentage of alpha motor fibres still conducting was obtained from the ratio of the $M$ response at the endpoint to the initial $\mathbf{M}$ response. All touch afferent fibres were considered to be conducting when the threshold was normal $(0.2 \mathrm{~g})$ and none when the threshold was greater than $1.4 \mathrm{~g}$. All afferent fibres carrying the sense of cutaneous vibration were considered to be conducting when the threshold was normal $(2 \mu \mathrm{m})$, and none when it was greater than $25 \mu \mathrm{m}$. At the endpoint of the study an estimate of the 'percentage of functioning fibres' was obtained from the fraction: (maximum threshold-threshold at endpoint/maximum threshold-normal threshold 
$\%)$. The degree of vibratory inhibition at the endpoint was obtained from the $\mathrm{H}$ vibration $/ \mathrm{H}$ control ratio at that time.

\section{Results}

The findings in a typical study are shown in Fig. 2. The pooled data from the seven studies are shown in the Table. The threshold to touch began to rise after a mean of $13 \mathrm{~min}$ of ischaemia. At the endpoint it was estimated that $15 \%$ of fibres carrying the sensation of touch were still conducting. The threshold to cutaneous vibration began to rise after a mean of $15 \mathrm{~min}$ of ischaemia. At the endpoint it was estimated that $5 \%$ of fibres carrying vibration were still conducting. Pinprick remained entirely normal (retaining its sharp localised quality) throughout all seven studies. The $M$ response was unaffected by ischaemia in two studies but declined slightly in amplitude (after a mean of $23 \mathrm{~min}$ of ischaemia) in the others. At the endpoint it was estimated that a mean of $76 \%$ of the alpha motor fibres were still conducting. The $\mathrm{H} / \mathrm{M}$ ratio remained unaltered (mean $58 \%$ at the beginning and $60 \%$ at the endpoint of the study). There was, evidently, little alteration in central excitability.

In all subjects there was an immediate decrease in the ATR/M ratio when the cuff was inflated. This was attributed to the mechanical effects of the cuff as it was noted (in a series of separate observations) that this effect was reversed immediately after the cuff was deflated, and that it could be reduced by moving the cuff proximally. The ATR/H ratio began to fall (from the new level established immediately after inflation) after a mean of $21 \mathrm{~min}$ of ischaemia, and was abolished (the endpoint of the study) at a mean of $27 \mathrm{~min}$.

The initial $\mathbf{H}$ vibration $/ \mathrm{H}$ control ratio was $21 \%$. The ratio began to increase after $21 \mathrm{~min}$ of ischaemia and rose to a mean of $70 \%$ at the endpoint of the study.

\section{Discussion}

The inhibition of the $H$ reflex by vibration of the tendo Achilles can be greatly reduced by blocking nerve conduction below the knee. The inhibition evidently arises from receptors in the lower leg. Can the size of the afferent fibres responsible for this inhibition be deduced from the nerve block that results from a tourniquet?

A cuff inflated around a limb results in ischaemia of the nerve under and distal to the cuff, deformation of the nerve under the cuff, and ischaemia of the end organs distal to the cuff. The
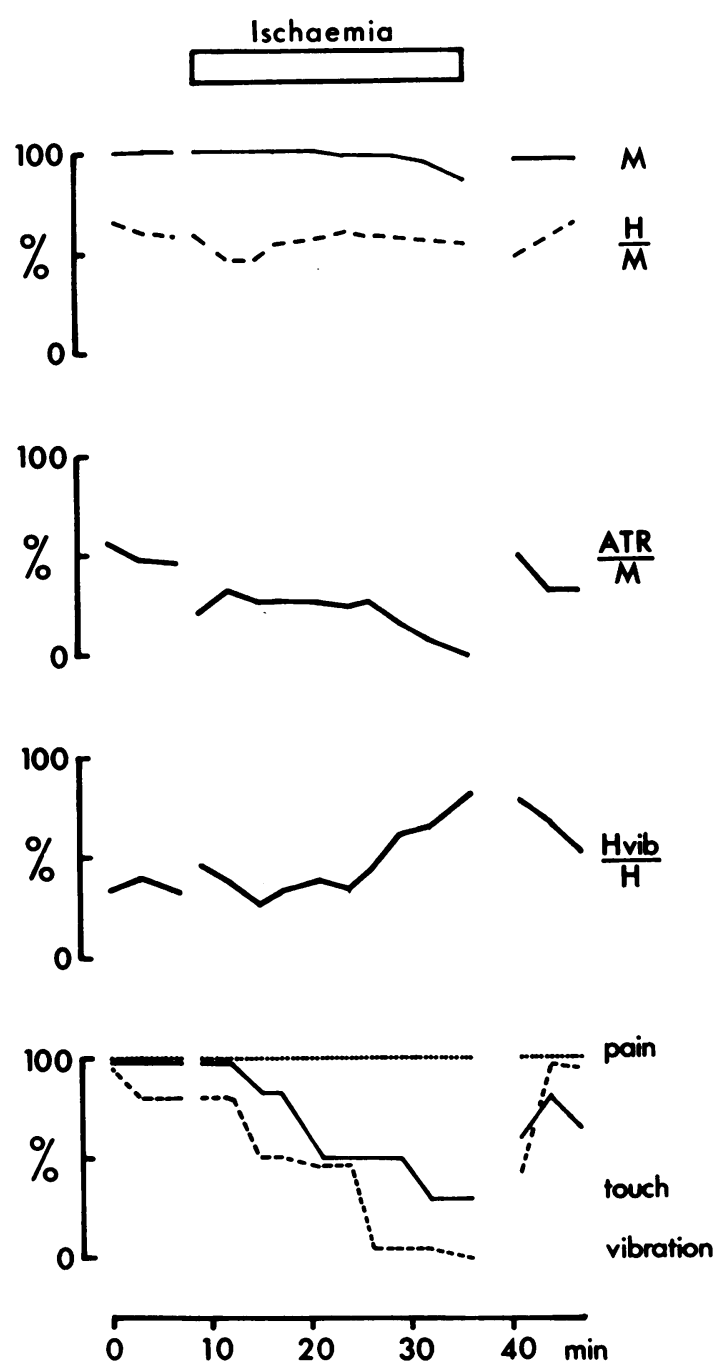

Fig. 2 Effects of inflating cuff below knee to $160 \mathrm{mmHg}$ (solid bar at top). The $M$ response, expressed as a percentage of its initial value, declines slightly as motor fibres become ischaemic. The $H / M$ ratio, expressed as a percentage (upper dashed line) does not change, indicating that a group I volley initiated above the cuff continues to activate a similar proportion of the motoneurone pool. The ATR/H ratio, expressed as a percentage (upper thick line), falls to zero as conduction fails in the large Ia afferent fibres distal to the cuff. The degree of vibratory inhibition ( $H$ vibration/H control ratio) expressed as a percentage (lower thick line) becomes less as the afferent fibres carrying this effect are blocked. The 'percentage of conducting fibres' (see text) carrying pinprick (...), touch (-), and vibration (upper dashed line) are shown at the bottom. Perception of discrete pain is unaffected by 26 min ischaemia. 
Table Estimates of the 'percentage of functioning fibres' of various sizes and the $H$ vibration/ $H$ control ratio when the ankle jerk was abolished by ischaemia

\begin{tabular}{|c|c|c|c|c|c|c|c|c|c|c|}
\hline \multirow[t]{2}{*}{ Subject } & \multirow{2}{*}{$\begin{array}{l}\text { Age } \\
(y r)\end{array}$} & \multirow[t]{2}{*}{$\operatorname{sex}$} & \multirow{2}{*}{$\begin{array}{l}\text { Ischaemia } \\
\text { (min) }\end{array}$} & \multicolumn{5}{|c|}{ Estimate of $\%$ conducting fibres } & \multicolumn{2}{|c|}{ H vib/H ratio $\%$} \\
\hline & & & & Ia & Touch & Vibration & Alpha motor & Pain & Initial & $\begin{array}{l}\text { When ATR } \\
\text { abolished }\end{array}$ \\
\hline $\begin{array}{l}1 \\
2 \\
3 \\
4 \\
5 \\
6 \\
7\end{array}$ & $\begin{array}{l}30 \\
31 \\
31 \\
37 \\
26 \\
39 \\
33\end{array}$ & $\begin{array}{l}\mathbf{M} \\
\mathbf{M} \\
\mathbf{F} \\
\mathbf{F} \\
\mathbf{M} \\
\mathbf{M} \\
\mathbf{M}\end{array}$ & $\begin{array}{l}29 \\
28 \\
27 \\
23 \\
33 \\
24 \\
25\end{array}$ & $\begin{array}{l}0 \\
0 \\
0 \\
0 \\
0 \\
0 \\
0\end{array}$ & $\begin{array}{r}33 \\
0 \\
0 \\
0 \\
0 \\
0 \\
75\end{array}$ & $\begin{array}{r}0 \\
0 \\
0 \\
32 \\
4 \\
0 \\
0\end{array}$ & $\begin{array}{r}85 \\
45 \\
80 \\
100 \\
57 \\
.100 \\
65\end{array}$ & $\begin{array}{l}100 \\
100 \\
100 \\
100 \\
100 \\
100 \\
100\end{array}$ & $\begin{array}{r}35 \\
55 \\
16 \\
1 \\
19 \\
10 \\
11\end{array}$ & $\begin{array}{l}79 \\
89 \\
52 \\
36 \\
81 \\
94 \\
57\end{array}$ \\
\hline Mean & 32 & & 27 & 0 & 15 & 5 & 76 & 100 & 21 & 70 \\
\hline
\end{tabular}

subject experiences tingling in the extremity followed by sensory loss and paralysis which proceeds centripetally (Lewis et al., 1931). These effects appear to result from the ischaemia rather than the deformation of the nerve (Lewis et al., 1931). Thus failure of nerve conduction occurs in segments of the nerve distal to the cuff (Magladery et al., 1950; Caruso et al., 1973); the pressure to which the cuff is inflated does not appear to be important (provided it is greater than arterial pressure), and additional cuffs applied to the limb do not have cumulative effects. When the cuff is released and the nerve is no longer directly compressed, recovery of function is delayed if the blood supply to the limb has been occluded locally (Lewis et al., 1931). Ischaemia of end organs is probably less important than ischaemia of nerve fibres. Thus the sensory abnormalities occur in a centripetal manner although all of the end organs are rendered equally ischaemic and muscle fibres will respond to direct electrical stimulation when motor axons have been blocked by ischaemia (Lewis et al., 1931).

It has been a consistent finding that, when a cuff is inflated around a limb, the sensation of touch is lost before that of discrete pain, and that dull pain and sympathetic function are the last to become affected (Lewis et al., 1931; Zotterman, 1933; Clark et al., 1935; Sinclair and Hinshaw, 1950; Landau and Bishop, 1953). The large group I afferent fibres are also affected early (Magladery et al., 1950). This has led to the conclusion that, in general, large fibres are affected before small ones (Lewis et al., 1933; Magladery et al., 1950). Direct pressure on a segment of a peripheral nerve appears to result in a similar differential block both in animals (Gasser and Erlanger, 1929; Clark et al., 1935; Leksell, 1945), and in man (Torebjörk and Hallin, 1973; Mackenzie et al., 1975). Although ischaemia affects large fibres before small ones the fibres do not fail exactly in order of size
(Lewis and Pochin, 1937). It is not possible, for example, to demonstrate a selective block of the larger alpha motor fibres before the smaller ones (Hershey and Wagman, 1966; Ruskin et al., 1967).

The centripetal progression of the sensory changes after the inflation of a cuff around a limb could be most readily explained if the effects of ischaemia depended on the length of the nerve rendered ischaemic (Lewis et al., 1931), and there is evidence that this is so. After a cuff has been applied around the upper arm for about 20 minutes, stimulation of the ulnar nerve at the elbow results in a contraction of proximal muscles (such as flexor carpi ulnaris) but not of the distal hypothenar group. The hypothenar muscles can nevertheless be activated by stimulation of the ulnar nerve at the wrist (Lewis et al., 1931; Magladery et al., 1950). Under similar circumstances the sensory action potential recorded at the elbow in response to stimulation of the fingers fails before the sensory action potential recorded at the wrist (Caruso et al., 1973). An alternative explanation for the latter finding is that the proximal segments of an ischaemic nerve fail first (Lewis et al., 1931; Groat and Koenig, 1946a, b; Magladery et al., 1950; Fox and Kenmore, 1967).

Although most of the reported effects of ischaemia can be explained on the basis of the length of the nerve rendered ischaemic and the greater susceptibility of large fibres, there may be additional factors. Motor fibres may be more resistant to ischaemia than sensory fibres (Magladery et al., 1950), weakness may appear in flexor muscles before extensors (Lewis et al., 1931; Sinclair et al., 1971), and changes may appear in the distribution of one peripheral nerve before another. Some of these differences may depend on the amount of direct pressure transmitted to individual peripheral nerves or their blood supply (Sinclair, 1948).

For the purposes of the present study, the soleus 
muscle fibres and spindles were considered to lie under the recording electrodes. Since cutaneous testing was also carried out at the same level any effects attributable to the length of nerves rendered ischaemic have been ignored. As in the previous reports, ischaemia appeared to block conduction in large fibres before small fibres. The ankle jerk was abolished while discrete pain sensation, carried in A-delta fibres (Landau and Bishop, 1953; Mackenzie et al., 1975), was unaffected. Touch sensation, carried in A-beta and gamma fibres (Mackenzie et al., 1975), and the sense of rapid vibration, however, were affected earlier than would be expected on the basis of size. It is possible that the medial sural nerve, which supplies the cutaneous area tested, might have suffered a greater restriction of its blood supply than deeper nerves (Sinclair, 1948), or that the tingling produced by ischaemia resulted in masking of sensation before the nerve was blocked (Nathan, 1958). The present findings suggest that, although large fibres are in general more susceptible to ischaemia than small ones, the differential block cannot be too finely graded.

At the endpoint in the present study (when the ankle jerk was abolished) the largest muscle afferent nerve fibres were assumed to be virtually completely blocked. The large cutaneous afferent nerve fibres were considered to be moderately affected, the alpha motor fibres only slightly affected, and the A-delta fibres spared. At this time the inhibition of the $H$ reflex by vibration of the tendo Achilles was greatly reduced. This suggests that the inhibitory effect is carried by large afferent fibres. The differential block produced by ischaemia in these studies, however, was insufficiently precise to distinguish between group I and group II muscle or large cutaneous afferent nerve fibres, and all that can be concluded with certainty is that afferent fibres that are larger than A-delta are responsible for the vibratory inhibition of the $\mathrm{H}$ reflex in man.

\section{References}

Ashby, P., and Verrier, M. (1975). Neurophysiological changes following spinal cord lesions in man. Canadian Journal of Neurological Sciences, 2, 91100.

Ashby, P., and Verrier, M. (1976). Neurophysiologic changes in hemiplegia. Possible explanation for the initial disparity between muscle tone and tendon reflexes. Neurology (Minneapolis), 26, 1145-1151.

Barnes, C. D., and Pompeiano, O. (1970). Inhibition of monosynaptic extensor reflex attributable to presynaptic depolarization of the group Ia afferent fibers produced by vibration of flexor muscle.
Archives Italiennes de Biologie, 105, 233-258.

Burke, D., Hagbarth, K.-E., Löfstedt, L., and Wallin, B. G. (1976). The responses of human muscle spindle endings to vibration of non contracting muscles. Journal of Physiology, 261, 673-693.

Caruso, G., Labianca, O., and Ferrannini, E. (1973). Effect of ischaemia on sensory potentials of normal subjects of different ages. Journal of Neurology, Neurosurgery, and Psychiatry, 36, 455-466.

Clark, D., Hughes, J., and Gasser, H. S. (1935). Afferent function in the group of nerve fibres of slowest conduction velocity. American Journal of Physiology, 114, 69-76.

Delwaide, P. J. (1973). Human monosynaptic reflexes and presynaptic inhibition. An interpretation of spastic hyperreflexia. In New Developments in Electromyography and Clinical Neurophysiology, Vol. 3, pp. 508-522. Edited by J. E. Desmedt, Karger: Basel.

Fox, J. L., and Kenmore, P. I. (1967). The effect of ischemia on nerve conduction. Experimental Neurology, 17, 403-419.

Gasser, H. S., and Erlanger, J. (1929). The role of fiber size in the establishment of a nerve block by pressure or cocaine. American Journal of Physiology, 88, 581-591.

Gillies, J. D., Lance, J. W., Neilson, P. D., and Tassinari, C. A. (1969). Presynaptic inhibition of the monosynaptic reflex by vibration. Journal of Physiology, 205, 329-339.

Groat, R. A., and Koenig, H. (1946a). Centrifugal deterioration of asphyxiated peripheral nerve. Journal of Neurophysiology, 9, 275-284.

Groat, R. A., and Koenig, H. (1946b). Centrifugal functional deterioration of asphyxiated motor nerve within the neural axis. Journal of Neurophysiology, 9, 463-469.

Hagbarth, K.-E. (1973). The effect of muscle vibration in normal man and in patients with motor disorders. In New Developments in Electromyography and Clinical Neurophysiology, Vol. 3, pp. 428-443. Edited by J. E. Desmedt. Karger: Basel.

Hershey, W. N., and Wagman, I. H. (1966). Effects of ischemia on range of conduction velocities and on facilitation in human motor nerves. Transactions of the American Neurological Association, 91, 246248.

Lance, J. W., Burke, D., and Andrews, C. J. (1973). The reflex effects of muscle vibration. Studies of tendon jerk irradiation, phasic reflex inhibition and the tonic vibration reflex. In New Developments in Electromyography and Clinical Neurophysiology, Vol. 3, pp. 444-462. Edited by J. E. Desmedt. Karger: Basel.

Landau, W., and Bishop, G. H. (1953). Pain from dermal, periosteal, and fascial endings and from inflammation. Electrophysiological study employing differential nerve blocks. Archives of Neurology and Psychiatry (Chicago), 69, 490-504.

Leksell, L. (1945). The action potential and excitatory effects of the small ventral root fibers to skeletal 
muscle. Acta Physiologica Scandinavica, 10, suppl. $31,1-84$.

Lewis, T., Pickering, G. W., and Rothschild, P. (1931). Centripetal paralysis arising out of arrested bloodflow to the limb, including notes on a form of tingling. Heart, 16, 1-32.

Lewis, T., and Pochin, E. E. (1937). Effects of asphyxia and pressure on sensory nerves of man. Clinical Science, 3, 141-155.

Mackenzie, R. A., Burke, D., Skuse, N. F., and Lethlean, A. K. (1975). Fibre function and perception during cutaneous nerve block. Journal of Neurology, Neurosurgery, and Psychiatry, 38, 865873.

Magladery, J. W., McDougal, D. B., and Stoll, J. (1950). Electrophysiological studies of nerve and reflex activity in normal man. II the effects of peripheral ischemia. Bulletin of the Johns Hopkins Hospital, 86, 291-312.

Nathan, P. W. (1958). Ischaemic and post-ischaemic numbness and paraesthesiae. Journal of Neurology, Neurosurgery, and Psychiatry, 21, 12-23.

Ruskin, A. P., Tanyag-Jocson, A., and Rogoff, J. B. (1967). Effect of ischemia on conduction of nerve fibers of varying diameters. Archives of Physical Medicine and Rehabilitation, 48, 304-310.
Sinclair, D. C. (1948). Observations on sensory paralysis produced by compression of a human limb. Journal of Neurophysiology, 11, 75-92.

Sinclair, D. C., and Hinshaw, J. R. (1950). A comparison of the sensory dissociation produced by procaine and by limb compression. Brain, 73, 480 498.

Sinclair, D. C., Matheson, A. B., and Skene, W. G. (1971). Motor paralysis during asphyxial block of the ulnar nerve. Journal of Neurology, Neurosurgery, and Psychiatry, 34, 51-56.

Torebjörk, H. E., and Hallin, R. G. (1973). Perceptual changes accompanying controlled preferential blocking of $\mathrm{A}$ and $\mathrm{C}$ fiber responses in intact human skin nerves. Experimental Brain Research, 16, 321332.

Wallin, B. G., Hongell, A., and Hagbarth, K.-E. (1973). Recordings from muscle afferents in parkinsonian rigidity. In New Developments in Electromyography and Clinical Neurophysiology, Vol. 3, pp. 263-272. Edited by J. E. Desmedt. Karger: Basel.

Zotterman, Y. (1933). Studies in the peripheral nervous mechanism of pain. Acta Medica Scandinavica, 80, 185-242. 